International Journal of Engineering \& Technology, 7 (4.33)(2018) 510-516.
International Journal of Engineering \& Technology
SPC
Website: www.sciencepubco.com/index.php/IJET
Research paper

\title{
Interactive Mobile Apps (CinTA 2.0) for Dyslexia's Children Malay Language Therapy Tool: Focus on Malay Language
}

\author{
Nur Hasni Nasrudin ${ }^{1 *}$, Rosida Ahmad Junid ${ }^{2}$, Siti Khatijah Nor Abdul Rahim ${ }^{3}$, Zainab Mohamed ${ }^{4}$, Anis Zafirah \\ Azmi $^{1}$, Ini Imaina Abdullah ${ }^{1}$ \\ ${ }^{I}$ Faculty of Computer and Mathematical Sciences, Universiti Teknologi MARA, Perak Branch, Tapah Campus, Tapah Road, \\ 35400 Perak, Malaysia \\ ${ }^{2}$ Academy of Language Studies, Universiti Teknologi MARA, Perak Branch, Tapah Campus, Tapah Road, \\ 35400 Perak, Malaysia \\ ${ }^{3}$ Faculty of Computer and Mathematical Sciences, Universiti Teknologi MARA, Shah Alam, 40450 Selangor, Malaysia \\ ${ }^{4}$ Faculty of Civil Engineering, Universiti Teknologi MARA, Shah Alam, 40450 Selangor, Malaysia \\ *Corresponding author E-mail: nurha932@perak.uitm.edu.my
}

\begin{abstract}
The implementation of mobile apps in the educational systems has kept abreast with the needs of specific learning disability (SLD) children. It was agreed by researchers that technology is able to aid and harness the language development of these children. The use of mobile applications in English language has been widely accepted and implemented among educators. However, it was discovered that most of the applications have scarcely adopted the Malay language as the main stream to aid Malay language development of these children. Thus, it is imperative to set the aim of this paper to introduce an interactive mobile apps that uses Malay Language as the Therapy Tool for the Dyslexic Children in improving their language learning processes. The uniqueness of this app falls on the aesthetic value that is implemented in CInTA 2.0. The app is user friendly which applied multi-sensory technique that is suitable for learners with language disorder, specifically dyslexic children.
\end{abstract}

Keywords: Specific learning disability (SLD); Dyslexia; Malay Language Therapy Tool; multi-sensory technique.

\section{Introduction}

Undeniably, educators are very virtuous and creative in organizing, managing and conducting classroom activities. Nevertheless, they always feel the "heat" at times when they are challenged with learners of "specific learning disabilities" (SLD), who need extra attention in the learning process. According to Florida Department of Education, a specific learning disability (SLD) is defined as "a disorder in one or more of the basic learning processes involved in understanding or in using language, spoken or written, that may manifest in significant difficulties affecting the ability to listen, speak, read, write, spell, or do mathematics" [1]. SLD can occur as a result of brain injury or minimal brain dysfunction which can lead to dyslexia, dyscalculia, dysgraphia, or developmental aphasia. Hence, the rigorousness of these specific learning disabilities, if not been monitored and cured can affect the reading fluency, the speech act, the words sounds (syllables), the spelling and writing of words and sentences. Therefore, it is imperative to think of an interactive, IT Savvy and digitalised technology that can aid their learning processes as well as generate interest in learning among them. According to [2], digital technologies can be used to train, assist and even enable the learning process. Specifically, designed applications may not only stimulate students' interest, but may also help students with disabilities to fit into and progress within the mainstream school environments. In other words, employing Information and Communication Technology (ICT) i.e. the use of Smart Phones will help children in addressing their language dis- orders at an early age and possibly mitigate its various negative effects before reaching adolescents $[2,3]$.

Based on the above scenario, one of the main groups of people that could potentially gain benefits from the integration of technology in aiding language disorder is the dyslexic children. In [4] and [5] explained the need of dyslexic pupils to access ICT for learning and being introduced to the appropriate ICT, including hardware and software (such as different word processors) for these pupils. The use of multimedia is also believed to assist dyslexic learners [6-9]. Dyslexia is a specific learning disability that is neurobiological in origin. It is characterized by difficulties with accurate and/or fluent word recognition and by poor spelling and decoding abilities [10]. Dyslexic children have significantly lower reading skills than expected, which will affect their visual-verbal responses. Besides, they also have difficulties with the phonological responses (the sounds of syllables and words) which will surely have great influence on their writing skills. Thomas regarded ICT as an enabler, as it can facilitate access to students by learning, increasing their motivation, fostering self-competition, enhancing their confidence and self-esteem [11]. Much research has been conducted in integrating Mobile Application in classroom activities to create more fun for the dyslexic children [12]. The mobile apps is believed to enable teaching and learning been transformed to a multi-sensory technique (touch, listen and visual) manner whilst giving them the option to choose from information, which will surely enrich their language skills and IT knowledge. According to [13], "mobile applications encourage children with dyslexia to carry out a larger number of exercises, and as for the 
children's interaction and learning through technology, it can progressively improve their mind mapping abilities".

Thus, it is the aim of this paper to introduce an interactive mobile apps as a Language Therapy Tool for the Dyslexic Children in improving their learning processes. However, the uniqueness of this language therapy tool (CinTA 2.0) is the use of Malay Language instead of English. It is hoped that the apps is able to offer digital teaching materials as complementary to existing teaching materials for the teachers and aid students in improving their reading and writing skills mainly in the Malay Language.

\section{Aesthetic Values of CinTA 2.0}

Users have vital stakes in any form of innovation. It is with great concern the introduction of the mobile apps is able to foster, develop and improve the language skills of the dyslexic children. From rigorous survey conducted, it was found that there were NOT MANY mobile apps in the Malay Language that have been commercialized to improve dyslexic children's language skills The "extinction" of such mobile apps in the Malay language is further emphasised and agreed by the President of Malaysian Dyslexia Association, Puan Sariah Amirin and the teachers. The survey conducted also reveals that conventional English language mobile apps is not able to function as a therapy tool to improve the children's Malay Language skills. This is due to the differences in the phonological, morphological and syntactical aspects of both languages. The need to develop an apps in the Malay Language is also supported by the Education Minister of Singapore, Mr. Heng Swee Hea at the Annual Malay Language Seminar organized by the Malay Language Center in Singapore [14]

"Our different races, including the Malay Community, are rich in heritage and cultures treasures. A strong grasp of language is the foundation that empowers people to explore their cultural assets".

Education Minister Heng

He further emphasizes that "The apps was an example of "harnessing technology" in learning mother tongue languages".

\section{Requirement Workflow}

Based on the in-depth discussions with Malaysian Dyslexia Association in Ampang, we have agreed to some specific requirements to develop a mobile application known as CinTA 2.0 to help dyslexic children to read texts written in Malay Language. The president and teachers in this organisation had given full commitments by giving suggestions, opinions and information to produce an apps as Malay Language therapy tools for dyslexic children. The use case diagram for this application is shown in Fig. 1.

Modules in this application are divided into two main modules; recognize and learn alphabet and learn syllable. In the first module, children will be recognizing alphabet name, alphabet sound, related animated short story, writing technique as well as interactive game. Once children are familiar with alphabet and have completed the first module, teacher will teach them the second module which is syllable. In the second module, the children will learn about consonant, vowel and how the alphabet can be transformed and rearranged to become a syllable. Among the examples are combination of consonant and vowel (KV) "bu", combination of consonant, vowel and consonant (KVK) "kak" and combination of vowel, consonant and vowel "ada". Pictures and words that are used are from the environment that every children are familiar with. Relevant games are also provided in the second game. Thus, children will enjoy while learning the Malay language using CinTA 2.0.

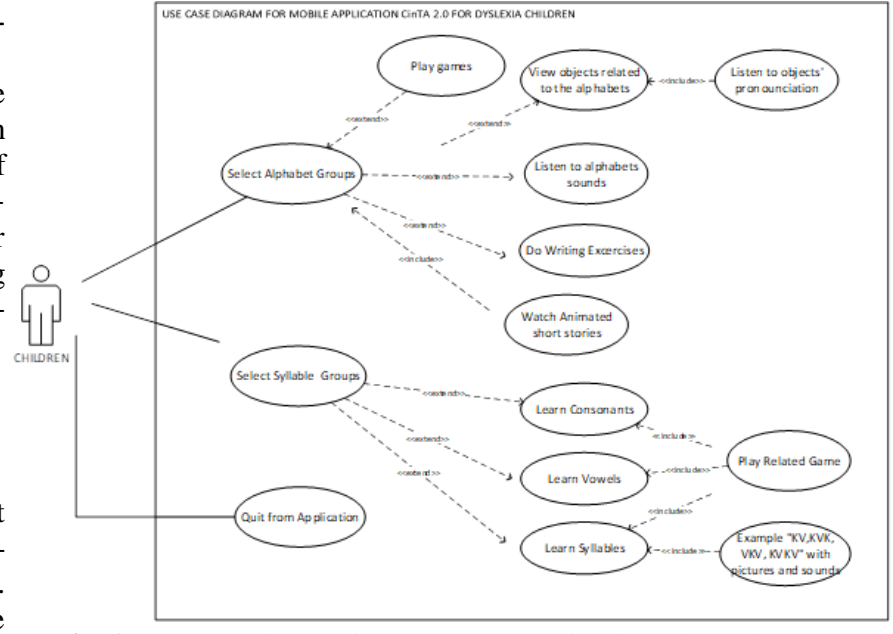

Fig. 1: Use case diagram from Cara Interaktif Tulis Abjad (CinTA) 2.0. It consists of two main modules and a number of sub modules to help teachers in Malaysian Dyslexia Association to teach dyslexic children for Malay Language subject beginner level.

For better understanding the flowchart of CinTA 2.0 is shown in Fig. 2.

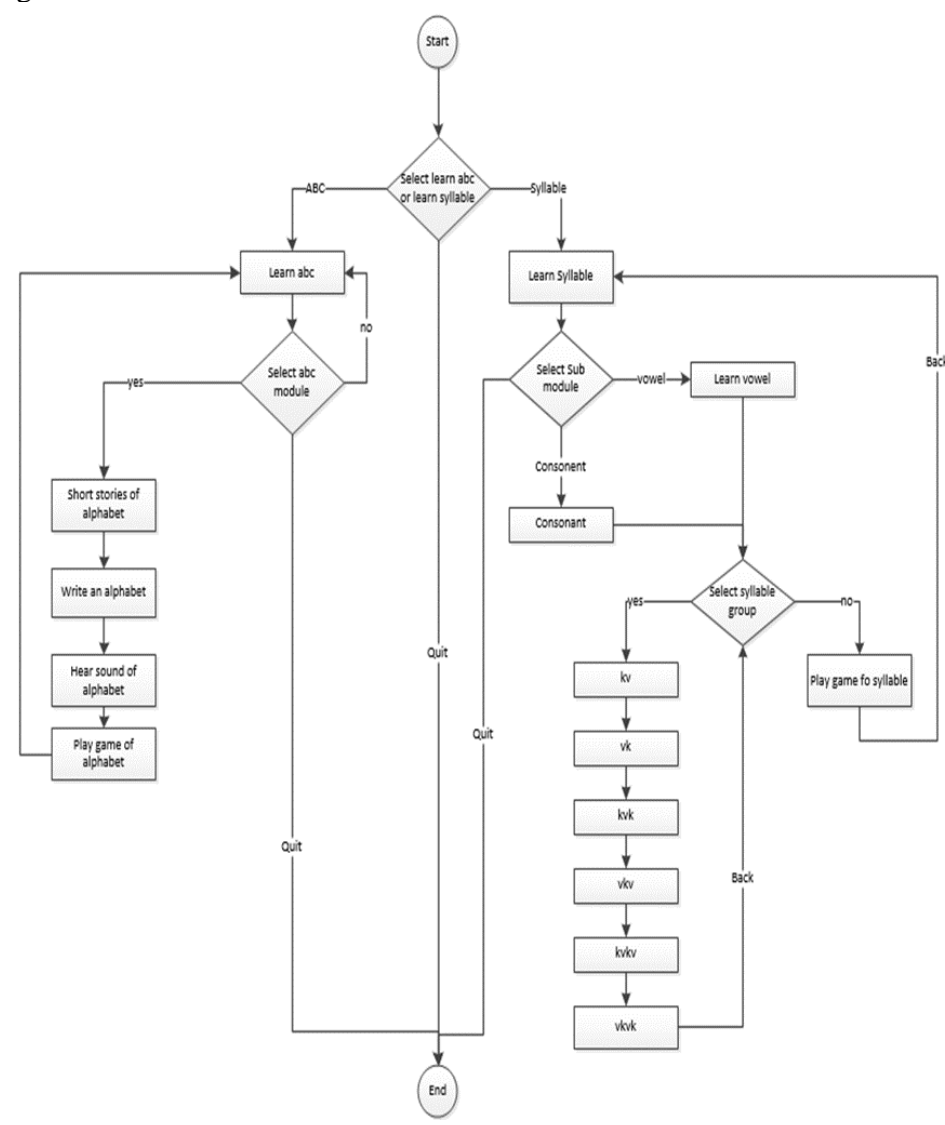

Fig. 2: Flow chart of Cara Interaktif Tulis Abjad (CinTA) 2.0 that shows interaction and linkages in the application.

Children will easily navigate from one module to another. For example, if a student has completed module 1 and well understood and know about the alphabet shape, sound and writing skills, he/she can freely jump to module 2 which is syllable. Meanwhile, they are able to learn $\mathrm{ABC}$ again at any time for revision purposes.

\section{Application Design}

The design of this application has been approved by the president and teachers from the Malaysian Dyslexia Association in Ampang. 
Other characteristics, requirements and features that have been considered and implemented in this mobile apps are:

i. All alphabets or letters in any activities in the mobile application need to be separated and showed separately to the children.

ii. Comic Sans MS is suggested to be the most suitable font type.

iii. Usage of phonics is encouraged for each alphabet.

iv. Example for an alphabet should not exceed 5 sentences (if sentences are constructed to demonstrate usage and meaning of alphabet)

v. The use of music as background during learning is encouraged.

vi. Background colour for the mobile application should be light or soft colours. Red colour should be avoided as the background.

vii. If any images or icons need to be used, it must be ensured that they are not put at one corner only to avoid the users from having the tendency to focus more on certain corners only.

viii. Do not ever use discouraging statements in the application such as "Sorry, your answer is wrong!" or "Wrong", but instead always use encouraging statements such as "Oops, try again!".

ix. Tips to get dyslexia children's attention during learning is by getting them participated in 5 minutes learning and then 5 minutes activity or assessment alternately.

$\mathrm{x}$. It is suggested by the teachers and parents to develop a mobile application in Bahasa Melayu (Malay Language), since currently the number of mobile apps using this language is very few.

xi. Any assessments designed for the children in the application are suggested not to be too difficult. They should be very clear and simple.

xii. Examples of common type of questions during quiz which are highly encouraged for the dyslexia students are for instance: "Tap on the letter that has the phonic sound....", "Draw the alphabet for......", and "Match the name with picture correctly".

xiii. Learning or assessment activities using puzzles are not encouraged for the dyslexic children because based on observations they tend to easily get bored through those activities.

xiv. Any texts shown in the app should come together with audio to assist them in understanding the instructions or notifications

xv. Any instructions or notifications meant to be given to the kids, for instance "Sila tekan butang" (Please click the button) or "Tahniah!" (Congratulations!) should use a cheerful voice to maintain their interests and focus.

The design of the mobile application proposed in this study was based on the requirements, opinions and suggestions from the president and teachers to ensure that the application is suitable and can really help dyslexic children to enhance their Malay Language understanding and to become Malay language therapy tools.

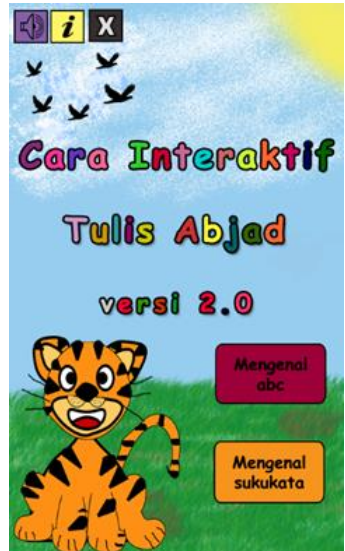

Fig. 3: Main menu of the application.

Soft blue (sky) and a green (grass) in Fig. 3 have been chosen as a background as it will help children to feel calm. On the other hand, happy tiger picture is used as a mascot that attracts and invites children to get to know more about this apps. In this menu, user can choose two buttons to start the activity which are "Mengenal abc" for the start module to learn abc or "Mengenal Sukukata" to learn about syllable. If the user wants to stop the sound that has been played, the user can click the sound button. For teachers, info button will present some information about this application to give them some idea about the apps.

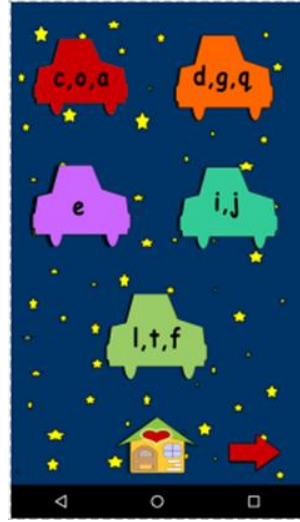

Fig. 4: A group of alphabet according to alphabet family. This module known as learn $\mathrm{ABC}$ "Mengenal abc".

When the user clicks the "Mengenal abc" button, page as in Fig. 4 will be displayed. The alphabets will be categorized based on how the alphabet is written. The user can click "coa" button or another group button to start the activity. The user can click home button to go back to the main page or click the next button to navigate to other pages. Instruction sound will be played automatically.

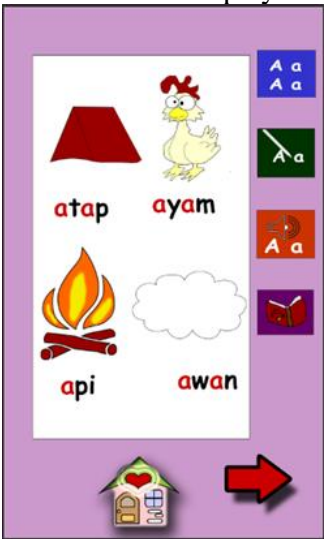

Fig. 5: Relevant picture to relate with the alphabet.

After the user clicked the "coa" button in "Mengenal abc" module, page as Fig. 5 will be displayed in which the video will be played. 
In this video, four examples of the alphabets will be shown with sounds and some animations. The user can control the video and click the "play" button to keep playing, "stop" button to stop the video, "rewind" button to re-play the previous video and the "pause" button to pause the video. Pictures that are used are simple and familiar in student environment and surrounding. The user can click the "home" button to go back to the Mengenal abc module to click other alphabets.

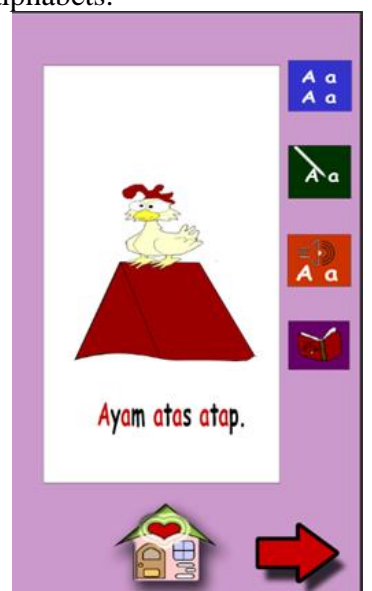

Fig. 6: Short story that combines picture with animated image and enjoyable song.

A display in Fig. 6 shown when user clicks the "Aa Aa" blue button, a short story which consists of a few sentences made up of words from the selected alphabet. We have been advised to emphasize on the sound of particular alphabets and provide sufficient time from one word to another. Hence, children will be able to recognize and remember the shape and sound (phonic) for a particular alphabet. We are also advised to include a joke (sense of humour element) in the story and let the children think of the logic of the story. This is because dyslexic children are always curious and love to reason and think in logical manner. The jokes will also make them happy and enjoy to continue learning Malay language.

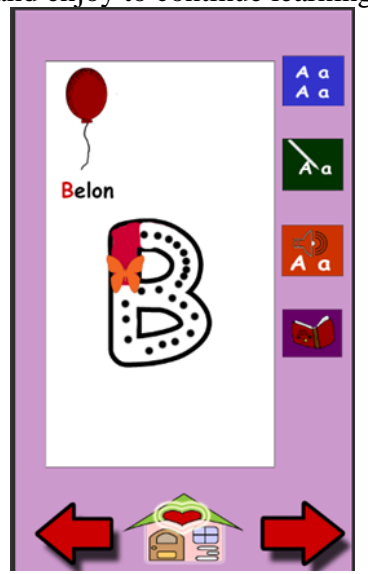

Fig. 7: Writing module for the student.

Page as Fig.7 will be displayed when the user clicks "Aa" green button with the pencil icon. The user can trace the alphabets selected. One example based on the chosen alphabet will be shown and the user can click the icon and the sound will be played. The shape of the alphabet is formed by a dotted line. A voice instruction will ask the student to move the butterfly through the alphabet shape. Butterfly represents the paint brush, thus when the butterfly moves, children will see and feel as if the butterfly is flying and this urges excitements among children.

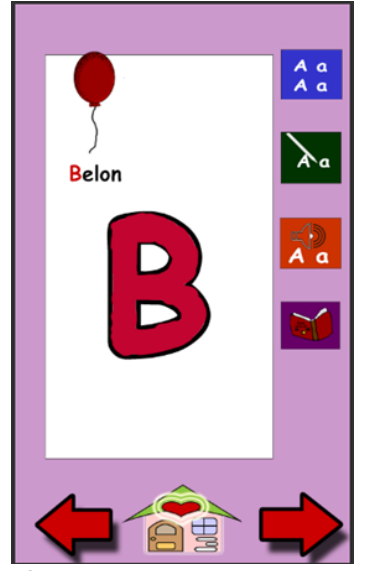

Fig. 8: Hearing a sound letter module.

When the user clicks the sound button, hearing a sound letter module page as in Fig. 8 will be displayed in which in this page the user can click the alphabet and the sound of it will appear. The object of the word and its sound will also be displayed and played when the user clicks the related button. If the user wants to go the next alphabet, the user can click the next button (an icon represented by the arrow icon pointing to the right) and click the previous button (an icon represented by the arrow icon pointing to the right) to go the previous page. The user can click the home button if she or he wants to go back to the main menu.

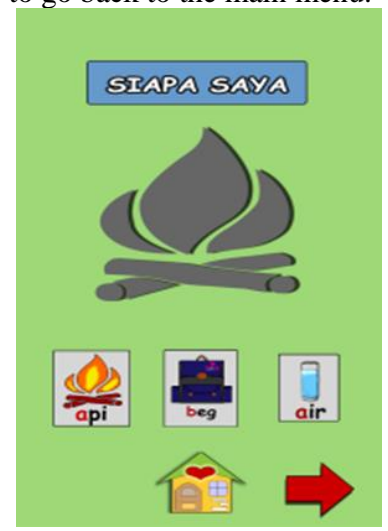

Fig. 9: Activity module after completed the learning module.

When children click the activity button, the game page will be displayed as shown in Fig. 9. A voice instruction will ask the children to guess and map the picture with small picture at the bottom of the page. The user can click the icon that appears as an example of alphabet and the sound of the alphabet will be played. The user can also click three pictures that are displayed to choose the answer and when the user gets the right answer, the app will navigate to the next exercise. The user needs to answer a question correctly before she or he can proceed to the next page.

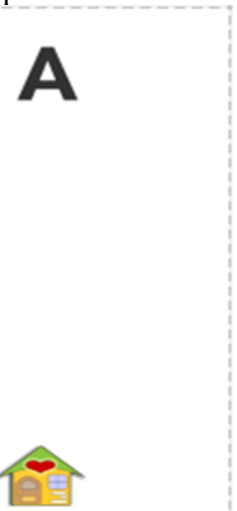

Fig. 10: Activity module after completed the learning module for writing skills. 
In activity module page as in Fig.10, the children need to write an alphabet that appears with the sound of the alphabet. Example of the alphabet is shown at the top of the page, and the children are requested to draw the alphabet shape in the paint area at the middle of the page. The teachers will accompany the children to complete the writing activity. The children are allowed to try as much as possible until they are satisfied.

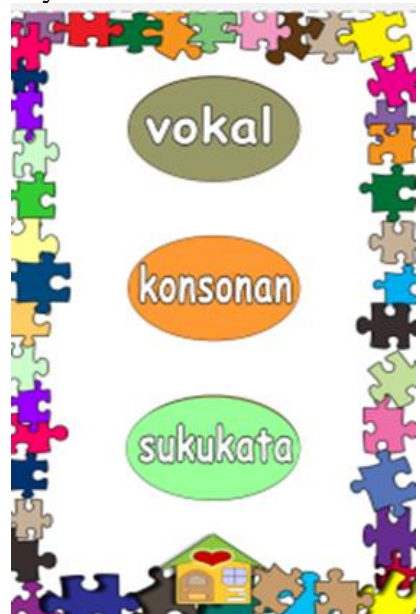

Fig. 11: Learning module of "mengenal sukukata".

This page in Fig. 11 will be displayed after the user clicks the "Mengenal Sukukata" (Syllable) module. This is the main module for "Mengenal Sukukata" that includes three modules which are "vokal", "konsonan" and "sukukata". The user can click the home button to go back to the main menu.

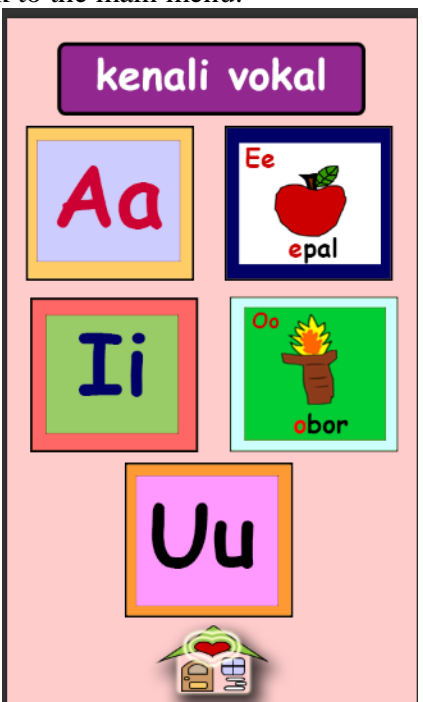

Fig. 12: Learn vowel "Mengenal vokal" module.

Learn vowel page as in Fig. 12 will be displayed after the user clicks the vokal button and all the vowel alphabets will be displayed. When one of the vowel is displayed, the user can see the video being played and the alphabets being shown. The video will play different songs with different background music, it is one of the mechanisms to attract and avoid them from being bored. The main page of sukukata will be displayed when the user clicks the home button.

When the user clicks the consonant module, the page as in Fig. 13 will be displayed. In this page, the user can click any alphabets to play the video in which the alphabets will be animated. The user can click the next button or the previous button to navigate to the next page or previous page. When the home button is clicked, the user can view the home page.

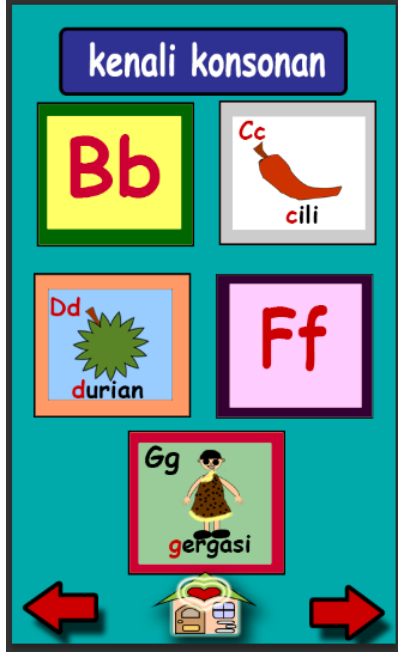

Fig. 13: Learn consonant "Mengenal konsonan" module.

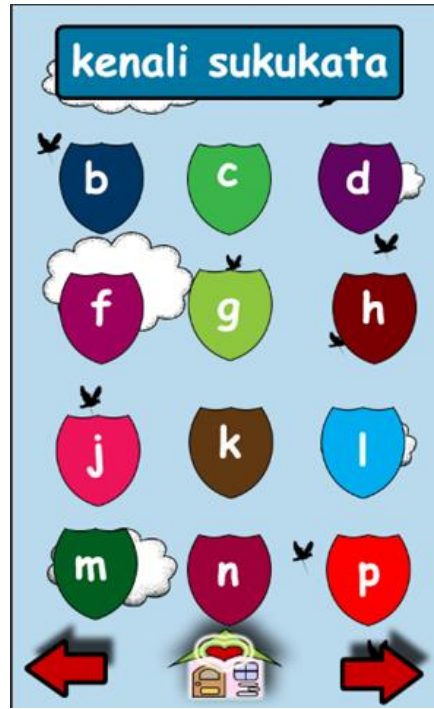

Fig. 14: Sukukata module using consonant alphabets.

The user will gain more knowledge in this module, where it will teach how to read. As in Fig. 14, the user can click any alphabets to start the activity that are related to reading. If the user wants to go back to the main page of sukukata module, the user can click the home button. If the user wants to go to the next page, the user can click the next button. When the user clicks the previous button, the previous page will be displayed.

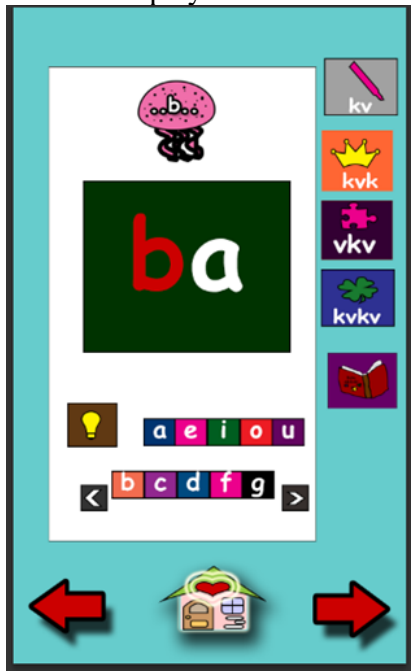

Fig. 15: Module "Mengenal suku kata" for the letter b. 
In the page shown as in Fig. 15, the user will be shown the box frame where the consonant will be combined with the vowel. The video will be played with the sound on how to pronounce the combined letters. The lamp button will display the vowel of alphabets and the video will be replaced based on the vowel that is clicked. The kv button will show this page when it is clicked, the kvk button will show a consonant mixed with vowel and consonant, the kvkv will show the page with mixed consonant and vowel with mixed consonant and vowel. The book button will display an activity for this section, where children will play match and map the alphabet to form a syllable.

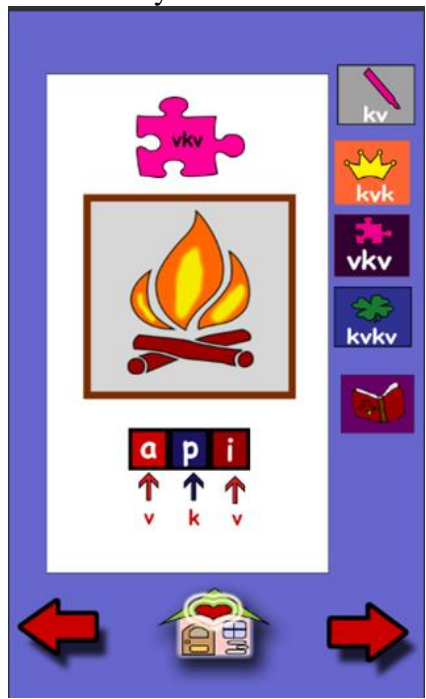

Fig. 16: Vkv module display this page

Fig. 16 is the next module when the user clicks the 'vkv' or 'kvk' button, this page will display example of an object and its syllable form based on the clicked button. This page will be displayed according to the selected button, for example if the user clicks the vkv button, a syllable in the form of a combination of vowel, consonant and vowel will be displayed. With this combination, the examples of words are "api", "abu" and others. The picture of the object will be displayed and its sound will be played after the user clicks the button. The boxes of aplhabets also play the sound of alphabets. When the user clicks the kvk module, the page will display in the same manner as the vkv module. The user can click the home button if she or he wants to go back to the main menu, click the next button to go to the next page and click on the previous button to navigate to the previous page.

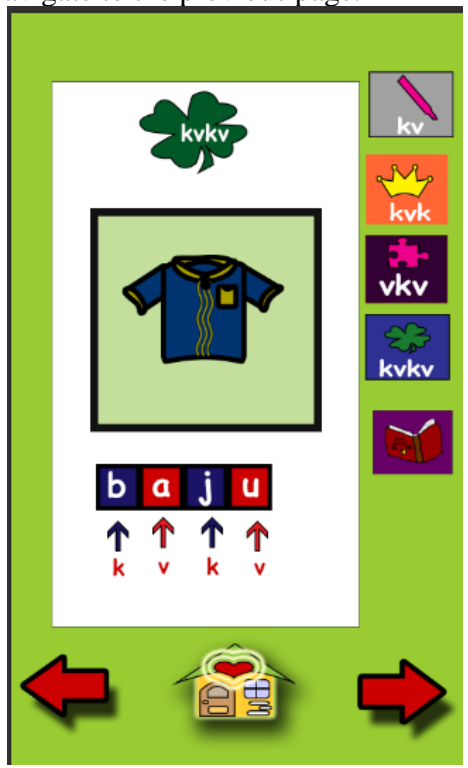

Fig. 17: Kvkv module display this page.
In this page, the user will be taught how to read and spell using mixed consonant with vowel and mixed consonant and vowel. As refers to Fig. 17 the example of the kvkv will be displayed with sound and the single alphabet also will be played too. The user can click the home button if the user wants to go to the main page, click the next button to navigate to the next page and click the previous button to navigate to the previous page.

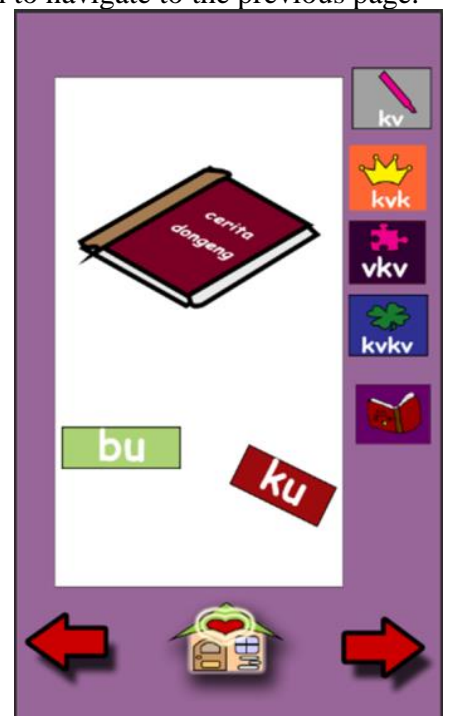

Fig. 18: Activity module for activity button.

Fig. 18 shows the last module in this application where in this page the user will be taught the next level of the syllable, which is consonant vowel (kv) combined with another consonant vowel (kv) to form a new word in the form of ' $k v k v$ '. The sound of the word will be played to let the children know the sound of the word and therefore they can relate it with the object. The user can click the main menu to go back to the main menu and the next button to go to the next activity and the previous button to go to the previous activity.

\section{Application Platform}

Platform is a crucial issue in developing an application. Therefore, in this section we will share about the development of platform as well as the user platform to run this application. It is shown in the Table 1.

Table 1: Hardware and software requirement for CinTA 2.0 .

\begin{tabular}{|c|c|}
\hline \multicolumn{2}{|c|}{ Platform for Mobile Development } \\
\hline Hardware & Software \\
\hline $\begin{array}{l}\text { 1. Operating system - Windows } 7 \\
\text { 2. Processor - Intel Core i5 } \\
\text { 3. RAM - 4.00 GB } \\
\text { 4. Samsung Galaxy A9 Pro } \\
\text { 5. Asus Zenpad C } 7.0 \\
\text { 6. Laptop Acer }\end{array}$ & $\begin{array}{l}\text { 1. Android Studio } 2.3 .3 \text { version } \\
\text { 2. Adobe Photoshop CS6 } \\
\text { 3. Adobe After Effects CS6 } \\
\text { 4. Audacity for sound editing } \\
\text { 5. Android version 5.1 (Jelly } \\
\text { Bean) (For Asus Zenpad C 7.0) } \\
\text { 6. Android version (Nougat) (For } \\
\text { Samsung Galaxy A9 Pro) }\end{array}$ \\
\hline \multicolumn{2}{|c|}{ Platform for User to Run CinTA 2.0} \\
\hline Hardware & Software \\
\hline $\begin{array}{l}\text { 1. Smartphone that using android } \\
\text { mobile operating system only } \\
\text { 2. Tablet that using android mobile } \\
\text { operating system only } \\
\text { **S Screen size will be automatically } \\
\text { resized and fit to phone screen size. }\end{array}$ & $\begin{array}{l}\text { 1. Android version } 5.1 \text { above } \\
\text { 2. API level } 21 \text { above }\end{array}$ \\
\hline
\end{tabular}

\section{Conclusion}

This paper proposed an interactive mobile application as a therapy tool to assist dyslexic children in improving their reading and 
writing skills in the Malay language. The Malay language has been chosen as the language used in the app due to the reason that apps available for this language are scarce and there is a serious need to develop an app to teach the Malay language to these children. This is supported by some evidences found during the literature study and field works conducted.

Requirements, design and modules in the app are discussed in detail to describe and illustrate the actual app. The app is user friendly which applied multi-sensory technique that is suitable for learners with language disorder, specifically dyslexic children. Victoriously, the app has received the copyright (intellectual property) acknowledgement from Research Innovation and Business Unit (RIBU), UiTM on 21st September 2017.

\section{Acknowledgement}

This work is financially supported by the Ministry of Education Malaysia and Universiti Teknologi MARA, Malaysia under iRAGS grant scheme with the number 600-RMI/DANA/ 5/3/IRAGS (51/2015).

\section{References}

[1] Florida Department of Education. (2018). Specific Learning Disabilities (SLD). http://www.fldoe.org/academics/exceptionalstudent-edu/ese-eligibility/specific-learning-disabilities-sld.

[2] Skiada, R., Soroniati, E., Gardeli, A., \& Zissis, D. (2014). EasyLexia: A mobile application for children with learning difficulties. Procedia Computer Science 27, 218-228.

[3] Madeira, J., Silva, C., Marcelino, L., \& Ferreira, P. (2015). Assistive mobile applications for dyslexia. Procedia Computer Science 64, 417-424.

[4] Keates, A. (2013). Dyslexia and information and communications technology: A guide for teachers and parents. Routledge.

[5] Madeira, J., Silva, C., Marcelino, L., \& Ferreira, P. (2015). Assistive mobile applications for dyslexia. Procedia Computer Science 64, 417-424.

[6] Rahman, F. A., Mokhtar, F., Alias, N. A., \& Saleh, R. (2012). Multimedia elements as instructions for dyslexic children. International Journal of Education and Information Technologies 6(2), 193-200.

[7] Balakrishnan, B., Chong, H. B., Idris, M. Z., Othman, A. N., Wong, M. F., \& Azman, M. N. A. (2017). Improving the English literacy skills of Malaysian dyslexic children: The case of culturally responsive mobile multimedia tool. Geografia-Malaysian Journal of Society and Space 11(13), 49-59.

[8] Balakrishnan, B., Chong, H. B., Idris, M. Z., Othman, A. N., Wong, M. F., \& Azman, M. N. A. (2017). Culturally responsive multimedia tool framework for dyslexic children in Malaysia: A preliminary study. Geografia-Malaysian Journal of Society and Space 12(3), 102-110.

[9] Alghabban, W. G., Salama, R. M., \& Altalhi, A. H. (2017). Mobile cloud computing: An effective multimodal interface tool for students with dyslexia. Computers in Human Behavior 75, 160-166.

[10] Rahim, S. K. N. A., Nasrudin, N. H., Azmi, A. Z., Junid, R. A., Mohamed, Z., \& Abdullah, I. I. B. (2018). Designing mobile application for dyslexia in reading disorder problem. International Journal of Academic Research in Business and Social Sciences 8(1) 628-646.

[11] Thomas, M. (2013). IT and students with emotional and behavioural difficulties. National Council for Educational Technology.

[12] Jamaludin, Z., Husni, H., \& Alobaedy, M. M. (2018). In search for a viable pedagogical agent in assistive applications for dyslexic children. Journal of Fundamental and Applied Sciences 10(6S), 1758-1770.

[13] Saleh, R., \& Alias, N. (2012). Learner needs analysis for mobile learning comic application among dyslexic children. International Journal of Education and Information Technologies 6(2), 185-192.

[14] New Mobile Apps teaches Malay words https://www.acpcomputer.edu.sg/index.php/new-mobile-appteaches-malay-words/ 